\title{
Short investigation on occurrence and removal of semivolatiles during wastewater treatment processes
}

\author{
MARIA DIANA PUIU ${ }^{1,2^{*}}$
}

${ }^{1}$ National Research and Development Institute for Industrial Ecology-ECOIND, 57-73 Drumul Podu Dambovitei, District 6, 060652, Bucharest

${ }^{2}$ University of Bucharest, Faculty of Biology, 91-95, District 5, 050095, Splaiul Independentei, Bucharest

*Corresponding author: diana_puiu@ymail.com

Received:

08.11 .2021
Accepted:

13.12.2021
Published:

17.12.2021

\begin{abstract}
The food industry wastewater is known to present a high organic matter content, due to specific raw materials and processing activities. Even if these compounds are not directly toxic to the environment, high concentrations in effluents could represent a source of pollution as discharges of high biological oxygen demand may impact receiving river's ecosystems. Identifying the main organic contaminants in wastewater samples represents the first step in establishing the optimum treatment method. The sample analysis for the non-target compounds through the GC-MS technique highlights, along with other analytical parameters, the efficiency of the main physical and biological treatment steps of the middle-size Wastewater Treatment Plant (WWTP).

Long chain fatty acids and their esters were the main abundant classes of non-target identified compounds. The highest intensity detection signal was reached by n-hexadecanoic acid or palmitic acid, component of palm oil, after the physical treatment processes with dissolved air flotation, and by 1-octadecanol after biological treatment.
\end{abstract}

Keywords: fatty acids, food industry, GC-MS, semivolatiles, wastewater, treatment processes

\section{INTRODUCTION}

Due to complex organic matrix of the wastewater samples, only targeted compounds, which are reported as hazardous by environmental authorities, are determined by analytical methods. The other chemical species, which are considered non-target compounds, are usually unknown and quantified along with all organic load as chemical and biochemical oxygen demand (COD and $\mathrm{BOD}_{5}$ ) or as total organic carbon. Low $\mathrm{BOD}_{5} / \mathrm{COD}$ ratios indicates the presence of low or nonbiodegradable compounds, especially carbonaceous species, which requires additional treatment methods as degradation, adsorption or advanced filtration. It was reported that the removal efficiency is determined by the bio/degradability characteristics of organic compounds and the specificity of treatment methods $[1,2]$.

The chemical compounds usually detected in the municipal sewage samples corresponds to different areas of activity, including pharmaceutical residues, byproducts or drug metabolites, personal care products, pesticides, flame-retardants, food additives, polycyclic aromatic hydrocarbons $(\mathrm{PAH})$, hormones, phenols, sweeteners, surfactants, naturally occurring amino acids etc. [3-5]. Compared to municipal wastewater samples, some industrial effluents may bring specific organic contaminants, especially molecular structure correlated compounds such as: halogenated isomers of dibenzo-p-dioxins and dibenzofurans [6], congeners and isomers of perfluorinated compounds from textile wastewater [7], class-correlated compounds as pesticides (thiabendazole, propiconazole, imazalil etc.) from agro-food industry of fruits and vegetables [8]. 
The detection of these non-target compounds with a mass-to-charge ratio lower than $1000 \mathrm{~m} / \mathrm{z}$ is done by screening analysis performed with gas chromatography or liquid chromatography techniques coupled with mass spectrometry. Usually, the compounds, tabulated by their volatility (non volatile, semivolatile or volatile) and solubility (polar or nonpolar) require different screening analytical methods [6-8].

The organic composition of effluents is notably influenced by WWTPs treatment methods, which are classified as primary, secondary and tertiary treatments. Non-target screening was effective in studies of the transformation products of specific contaminant degradation after $\mathrm{UV} / \mathrm{H}_{2} \mathrm{O}_{2}$ treatment. Jaen-Gil et al. used non-target screening methods in analysis of controlled contaminated hospital and industrial wastewater with metoprolol and metoprolol acid. After several treatment methods the main identified by-products were characterized as developmentally toxic, persistent and bio accumulative [9]. Other study have shown the presence of 33 pharmaceutical and their 113 by-products in wastewaters from hospitals, from a campus university and from an urban WWTP after fungal treatment with Trametes Versicolor [10]. With the use of sodium hypochlorite as disinfection agent for wastewater streams inadvertently generates new halogenated species, but without known formula [11]. Combining the hybrid membrane aerated biofilm reactor (MABR) system with ozone-biological activated carbon treatment, only 26 of the initial 90 compounds remained in effluent, where butyl trichloroacetate, trichloronitromethane and isopropyl myristate where some of the most refractory compounds [12].

Based on effluents ecotoxicity, the food industry generates less toxic pollutants in the effluents. For example, food ingredients of chocolate factory lead to an organic rich industrial effluent containing especially: fats, lactose, proteins and their derivatives [13].

\section{MATERIALS AND METHODS}

\section{Wastewater samples}

The studied samples are wastewaters generated by a middle size food processing plant from Romania. The samples were collected as grab samples, , after each of the main treatment steps of the wastewater treatment system: flow equalization tank, ET (S1), dissolved air flotation process, DAF (S2), and biological treatment with activated sludge (S3). The hydraulic retention time was not considered in sample prelevation. The samples were characterized for chemical and biological oxygen demand, $p \mathrm{H}$, total suspended solids (TSS) and solvent extractable organic matter.

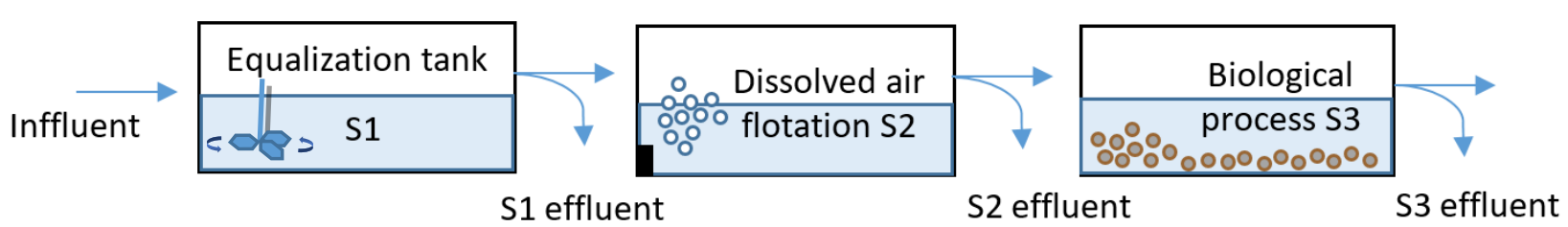

Fig. 1. WWTP flow diagram and sampling points

The flow equalization tank (fig. 1) is an operational unit of physical pretreatment stage in order to balance the variation of main contaminants concentration (to homogenize the water sample composition) and to better control the flow according to treatment capacity. In order to achieve this, mixers are used, which are also favorable in water aeration. The oxygen acts as an oxidant to the biodegradable compounds, which may increase the water treatability as decreasing the BOD level. In addition, it enhances the odour removal [2].

Dissolved air flotation operation is a non-conventional physical process that consists in the propulsion of suspended particles by air bubbles. The air purged (at high pressure) from the bottom of a DAF tank, forms fine bubbles that attaches to solid particles. These particles are brought to the water surface from where they are subsequently removed by skimming. Through this process 
suspended solids, oils and other lipophilic contaminants, which are adsorbed to sediments, are removed $[2,14]$.

Biological treatment involves the biodegradation of chemical species by microorganisms that use them as energy and nutrient source. The activated sludge process, due to low operation costs is a preferred technique in the treatment of wastewaters of diverse origins including municipal, agricultural or even industrial wastewaters containing pesticides due to improved efficiency of removing some refractive compounds as beta-blockers and other pharmaceutical compounds as ibuprofen, naproxen, and ketoprofen, but also in reducing the extracellular polymeric substances $[15,16]$.

\section{Sample extraction}

Screening analysis was done using a gas chromatograph technique with an adapted EPA method [17]. Due to the high content in organic compounds, a small, unfiltered volume of $250 \mathrm{~mL}$ fresh sample ( $\mathrm{pH} 7$ ) was extracted by liquid-liquid extraction method (LLE) with $50 \mathrm{~mL}$ hexane (Merck), and then dried with anhydrous sodium sulfate (Honeywell Fluka). The extract was concentrated to 1 $\mathrm{mL}$ hexane at $40^{\circ} \mathrm{C}$ constant temperature on a water bath, under a light stream of nitrogen. The samples were not filtered.

\section{GC-MS method}

Unknown compounds were determined by using GC Thermo 3310 equipment with mass spectrometer Evo 8000 with electron ionization (EI) module. A volume of $1 \mu \mathrm{L}$ extract was injected in split mode $(1: 5)$ at $200^{\circ} \mathrm{C}$; then purged with $1 \mathrm{~mL} / \mathrm{min}$ helium through the HP-5SilMS column $(60$ $\mathrm{m} \times 0.25 \mathrm{~mm} \times 0.25 \mu \mathrm{m}$, Thermo). The oven program was $50{ }^{\circ} \mathrm{C}(1 \mathrm{~min})$, gradient $10{ }^{\circ} \mathrm{C} / \mathrm{min}$ to 300 ${ }^{\circ} \mathrm{C}(16 \mathrm{~min})$. The ionization source was at $250{ }^{\circ} \mathrm{C}$. Only semivolatiles compounds with molecular mass and ion fragments corresponding to $50-500 \mathrm{~m} / \mathrm{z}$ domain were analyzed. The ion mass scan starts at $130{ }^{\circ} \mathrm{C}(\min 9)$.

\section{Data processing}

By applying the mentioned methodology, a chromatogram was obtained for each sample. Every chromatogram was automated and then manually filtered and processed with TraceFinder, Xcalibur and Amdis 2.72 softwares by applying the criteria as blank subtraction, peak deconvolution and minimum peak area of $1.0 \mathrm{e}^{7}$. The accurate identification spectra was realized by using the NIST MS 2.2 library (242466 spectra) with a search algorithm based on fragmentation ions, isotope pattern with correlation scores $>750$ and matching exact mass $>75 \%$. The separation between residual and moderated to high concentration compounds is based on a value of the signal-to-noise ratio $(\mathrm{S} / \mathrm{N})$ less, respectively above 30 . The analysis of residual contaminants established in this paper for 10$30 \mathrm{~S} / \mathrm{N}$, was not possible due to rich in organic matter content of wastewater, high background signals in mass spectrum, and low chromatographic resolution between isomers.

\section{Reagents}

For quality control of the applied GC-MS method, was additional tests were performed on high concentrations target analysis with phthalates mix (Sigma Aldrich) and residual concentrations target analysis with organochlorinated pesticides (Sigma Aldrich) and polychlorobyphenyls (Dr. Ehrenstorfer).

\section{RESULTS AND DISCUSSION}

\section{Occurrence of the organic compounds in wastewater samples}

The specified method is limiting the detection only to the semivolatiles compounds with low polarity to non-polar, while the range of high volatiles and non-volatiles compounds was not investigated. The detected compounds were classified in three levels:

- Level 1 - known compounds with matching spectra $>750$ and peak purity above $10 \%$, 
- Level 2 - mixture of isomers with matching spectra $>900$ and peak purity $<10 \%$,

- Level 3 - unidentified compounds with matching spectra $<750$ and variable peak purity.

A total of 70 different known organic substances were identified for all tested samples, where 35 are confirmed for $S 1,40$ for $S 2$ and 37 for $S 3$. The area of the peaks associated with identified peaks is represented by a percentage of $76.49 \%, 94.96 \%$ and $88.68 \%$ of the total area for $S 1, S 2$ and $S 3$. A graphical representation of the level area distribution is represented graphically in fig. 2, as well as the classification of compounds by chemical classes or groups like esters including phthalates, fatty acids and acids, ketones, alcohols, aldehydes, alkanes and haloalkanes, musks and terpenes, aniline, auxin and a triazinic derivative.

For all samples were identified long chain fatty acids (LCFA) esters with aliphatic chains consisting of 13-19 carbon atoms (C13-C19). These fatty acid esters (FAE) are, theoretically, the result of fatty acids reaction with alcohols. Saturated FAE with short chain (C1-C3) and long chain alcohol precursor (C9-C18), and unsaturated FAE with short chain alcohol precursor (C1-C3) were detected for these water samples.

A high number of esters were identified in all samples, while the highest area is assigned to LCFA for $S 1$ and $S 2$ samples. Out of a total of 18 carboxylic acid esters $(S 1)$, only 11 correspond to a long chain with at least 12C, while 3 are phthalates, 2 are glycerol acetates (di and triglyceride) and 2 are other types (a plasticizer and a flame retardant, tris(2-chloroisopropyl)phosphate, and an odor, kharismal). Other musks are versalide and galaxolide, two synthetic compounds. In table 1 are presented the Level 1 compounds and their identification status for $S 1-S 3$ samples. The $S 1$ fatty acids are saturated carboxylic acids with 10-18 carbon atoms in aliphatic structure, and for $S 2$ was identified a monounsaturated fatty acid named oleic acid, a C18 acid with one double bond. As can be seen, the esters and their derivatives: aldehydes, ketones and alcohols correspond to known fatty acids as palmitic acid (n-hexadecanoic acid), stearic acid (n-octadecanoic acid), oleic acid (9-cisoctadecenoic acid), lauric acid (n-dodecanoic acid) and caprylic acid (n-octanoic acid) which are usually found in palm oil [18], an oil used frequently in sweet products but which is suspected to be harmful to human organism by generating reactive oxygen species, ROS [19]. Also an oil is squalene, a triterpene and a polyunsaturated C30 oil secreted by shark liver. Another triterpene is $\beta$ amyrone, an antifungal compound present in some medicinal plants [20], which could be used in the food industry. Natural auxin, a plant growth hormone named indole, was detected in low concentration in the first system. Indole is naturally found in plants as Passiflora incarnata L. (passionflower) [21].

The detected tributyl acetylcitrate is used as a flavouring agent [22] but could be also a food packaging plasticizer residue, obtained from tributyl citrate acetylation. It is also a potential substitute for bis(2-ethylhexyl) phthalate and diisononyl phthalate. In high concentration, it is toxic for some amphibians: $13.3 \mathrm{mg} / \mathrm{L}$ LC50 for 4 days [23]. Tributyl citrate is an effective plasticizer for food packaging with biodegradable polymers, but can be also found in cleaning products among 2(phenylmethylene)-octanal. The octanal aldehyde is also used as biocide for disinfection or pest control [24].

Considering a direct relationship between area and chemical species concentration, the contaminants with highest concentration in $S 1$ and $S 2$ samples belongs to n-hexadecanoic acid (palmitic acid) while 1-octadecanol for $S 3$, as it is shown in fig. 2. As a final product in effluents, 1octadecanol could be a concern for environmental pollution. However, its persistence is low (biodegradable with a half-life of approximately 28 days, and a half-life of 5.7 hours under UV radiation) and its impact aquatic toxicity is also low, where fishes metabolize the fatty alcohols for growth, reproduction and supplying energy. The US Environmental Protection Agency concludes that this alcohol is not a high-priority substance [25]. Moreover, a recent study found out that its presence, along with the occurrence of 1-hexadecanol, prevents the water evaporation (an issue for agroindustry) due to forming a diffusion barrier monolayer at water surface [26], but also, inhibits the surface binding of $\mathrm{Zn}^{2+}$ [27]. The sum of compounds with an area less than 5\% is up to $42.5 \%$ for $S 1,25.0 \%$ for $S 2$ and $29.0 \%$ for $S 3$. 
Table 1. List of identified compounds, their occurrence (green cell) in S1-S3 samples and their lipophilicity constant (grey colour for the mixture of isomers eluted at the same retention time)

\begin{tabular}{|c|c|c|c|c|c|c|c|c|}
\hline $\begin{array}{c}\text { Classification } \\
\text { group }\end{array}$ & Compound & No. & CAS & S1 & $S 2$ & $S 3$ & Other names & $\log \mathbf{P}$ \\
\hline \multirow{17}{*}{$\begin{array}{c}\text { Carboxylic } \\
\text { acid esters } \\
\text { coresponding } \\
\text { to minim C12 } \\
\text { alkanes }\end{array}$} & Dodecanoic acid, 1-methylethyl ester / C12:C3 & 1 & $10233-13-3$ & & & & Isopropyl laureate & 6.37 \\
\hline & Dodecanoic acid, isooctyl ester / C12:C9 & 2 & $84713-06-4$ & & - & - & 4-Octanyl laurate & 9.03 \\
\hline & Dodecanoic acid, dodecyl ester / C12:C12 & 3 & $13945-76-1$ & - & - & & Lauryl laurate & 11.3 \\
\hline & Dodecanoic acid, hexadecyl ester / C12:C16 & 4 & $20834-06-4$ & & - & - & Cetyl laurate & 13.5 \\
\hline & Tetradecanoic acid, ethyl ester / C14:C2 & 5 & $124-06-1$ & - & & - & Ethyl myristate & 7.09 \\
\hline & Tetradecanoic acid, 1-methylethyl ester / C14:C3 & 6 & $110-27-0$ & & & & Isopropyl myristate & 7.43 \\
\hline & Hexadecanoic acid, methyl ester / C16:C1 & 7 & $112-39-0$ & & & & Methyl palmitate & 7.62 \\
\hline & Hexadecanoic acid, ethyl ester / C16:C2 & 8 & $628-97-7$ & - & & - & Ethyl palmitate & 8.15 \\
\hline & Hexadecanoic acid, hexadecyl ester / C16:C16 & 9 & $540-10-3$ & & & - & Cetyl palmitate & 15.6 \\
\hline & Hexadecanoic acid, octadecyl ester / C16:C18 & 10 & $2598-99-4$ & - & & - & Lanolin or stearyl palmitate & 15.6 \\
\hline & 1-(+)-Ascorbic acid 2,6-dihexadecanoate / C16 & 11 & $28474-90-0$ & - & & & Ascorbic acid, 2,6-dipalmitate & 14.0 \\
\hline & Octadecanoic acid, methyl ester / C18:C1 & 12 & $112-61-8$ & - & - & & Methyl stearate & 8.68 \\
\hline & Octadecanoic acid, ethyl ester / C18:C2 & 13 & $111-61-5$ & & & & Ethyl stearate & 9.21 \\
\hline & Heptadecanoic acid, 16-methyl-, methyl ester / C18:C1 & 14 & $5129-61-3$ & - & - & & Methyl isostearate & 8.49 \\
\hline & Octadecanoic acid, 1-methylethyl ester / C18:C3 & 15 & $112-10-7$ & & & & Isopropyl stearate & 9.56 \\
\hline & Octadecanoic acid, octadecyl ester / C18:C18 & 16 & $2778-96-3$ & - & & - & Stearyl stearate & 17.8 \\
\hline & Octadecanoic acid, 17-methyl-, methyl ester / C19:C1 & 17 & $55124-97-5$ & & - & - & 17-methyl Stearic Acid methyl ester & 9.03 \\
\hline \multirow{5}{*}{$\begin{array}{l}\text { Carboxylic } \\
\text { acid esters } \\
\text { coresponding } \\
\text { to } \mathrm{C} 12 \text { alkenes }\end{array}$} & 9-Hexadecenoic acid, ethyl ester / C16:C2 & 18 & $54546-22-4$ & - & - & & Palmitelaidic acid ethyl ester & 7.63 \\
\hline & 11-Octadecenoic acid (Z)-, methyl ester / C18:C1 & 19 & $52380-33-3$ & - & - & & Methyl cis-Vaccenate & 8.16 \\
\hline & 9-Octadecenoic acid (Z)-, methyl ester / C18:C1 & 20 & $112-62-9$ & - & - & & Methyl oleate & 8.16 \\
\hline & (E)-9-Octadecenoic acid, ethyl ester / C18:C2 & 21 & $6114-18-7$ & - & & - & Ethyl elaidate & 8.69 \\
\hline & (Z)-9-Octadecenoic acid, ethyl ester / C18:C2 & 22 & $111-62-6$ & - & & - & Ethyl oleate & 8.69 \\
\hline \multirow[t]{7}{*}{ Other esters } & Glycerol triacetate & 23 & $102-76-1$ & & & - & Triacetin & -0.24 \\
\hline & Glycerol 1,2-diacetate & 24 & $102-62-5$ & & & - & Diacetin & -0.54 \\
\hline & 2-Butenedioic acid (Z)-, dibutyl ester & 25 & $105-76-0$ & - & & - & Dibutyl maleate & 3.81 \\
\hline & Tributyl acetylcitrate & 26 & $77-90-7$ & - & - & & - & 6.92 \\
\hline & Tributyl citrate & 27 & $77-94-1$ & - & - & & - & 4.68 \\
\hline & Pentanoic acid, 5-hydroxy-, 2,4-di-t-butylphenyl ester & 28 & - & - & & & - & 4.82 \\
\hline & Octanoic acid, cyclohexyl ester / C8:C6 & 29 & $1551-42-4$ & & - & - & - & 5.93 \\
\hline \multirow[t]{4}{*}{ Alcohol } & 1,3-Diphenyl-2-propanol & 30 & $5381-92-0$ & & - & - & - & 3.20 \\
\hline & 1-hexadecanol / C16 & 31 & $36653-82-4$ & - & - & & Palmityl alcohol & 7.25 \\
\hline & Hexadecen-1-ol, trans-9- / C16 & 32 & $64437-47-4$ & - & - & & Palmitoleyl alcohol & 6.73 \\
\hline & 1-Octadecanol / C18 & 33 & $112-92-5$ & - & - & & Stearyl Alcohol & 8.31 \\
\hline Aldehyde & Octanal, 2-(phenylmethylene)- & 34 & $101-86-0$ & & & & $\alpha$-Hexylcinnamaldehyde & 5.33 \\
\hline
\end{tabular}




\begin{tabular}{|c|c|c|c|c|c|c|c|c|}
\hline \multirow{7}{*}{$\begin{array}{l}\text { Saturated fatty } \\
\text { acid }\end{array}$} & Decanoic acid / C10 & 35 & $334-48-5$ & & - & - & Capric acid & 4.09 \\
\hline & Dodecanoic acid / C12 & 36 & $143-07-7$ & & - & - & Lauric acid & 4.60 \\
\hline & Tetradecanoic acid / C14 & 37 & $544-63-8$ & & - & - & Myristic acid & 6.11 \\
\hline & Pentadecanoic acid / C15 & 38 & $1002-84-2$ & & - & - & - & 6.62 \\
\hline & n-Hexadecanoic acid / C16 & 39 & $57-10-3$ & & & & Palmitic acid & 7.15 \\
\hline & Octadecanoic acid / C18 & 40 & $57-11-4$ & & - & - & Stearic acid & 8.23 \\
\hline & (9Z)-Octadecenoic acid / C18 & 41 & $112-80-1$ & - & & - & Oleic acid & 7.70 \\
\hline \multirow[t]{3}{*}{ Ketones } & 2-pentadecanone / C15 & 42 & $2345-28-0$ & & & - & - & 6.22 \\
\hline & 2-heptadecanone / C17 & 43 & $2922-51-2$ & & & - & - & 7.28 \\
\hline & 2-nonadecanone / C19 & 44 & $629-66-3$ & & - & - & - & 8.34 \\
\hline \multirow{10}{*}{$\begin{array}{l}\text { Alkanes and } \\
\text { haloalkanes }\end{array}$} & Undecane, 2,7-dimethyl / C13 & 45 & $17301-24-5$ & - & - & 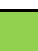 & - & 7.30 \\
\hline & Dodecane, 2,6,10-trimethyl- / C15 & 46 & $3891-98-3$ & - & - & - & Farnesane & 8.17 \\
\hline & Dodecane, 2,7,10-trimethyl- / C15 & 47 & $74645-98-0$ & - & - & - & - & 8.17 \\
\hline & Pentadecane, 2,6,10-trimethyl- / C18 & 48 & $3892-00-0$ & - & & - & Norpristane & 9.77 \\
\hline & Undecane, 1-iodo / C11 & 49 & $4282-44-4$ & - & & - & - & 6.81 \\
\hline & Tetradecane, 1-iodo- / C14 & 50 & 19218-94-1 & - & & - & Myristyl iodide & 8.40 \\
\hline & Dodecane, 1-iodo- / C12 & 51 & $224-293-1$ & - & & - & Lauryl iodide & 7.34 \\
\hline & Hexadecane, 1-iodo / C16 & 52 & $544-77-4$ & - & & - & n-cetyl iodide & 9.47 \\
\hline & Cycloheptane, methyl / C8 & 53 & $4126-78-7$ & - & - & 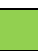 & - & 4.44 \\
\hline & Cyclotetradecane / C14 & 54 & $295-17-0$ & - & - & & - & 7.90 \\
\hline \multirow[t]{3}{*}{ Musks } & Kharismal & 55 & $24851-98-7$ & & & - & Methyl dihydrojasmonate & 2.50 \\
\hline & Versalide & 56 & $88-29-9$ & & - & - & Acetylethyltetramethyltetralin & 6.41 \\
\hline & Galaxolide & 57 & $1222-05-5$ & & & 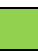 & Hexamethylindanopyran & 6.23 \\
\hline \multirow[t]{5}{*}{ Phthalates } & Dibutyl phthalate & 58 & $84-74-2$ & - & - & - & DBP & 4.50 \\
\hline & Diisobutyl phthalate & 59 & $84-69-5$ & - & - & & DIBP & 4.46 \\
\hline & Bis(2-ethylhexyl) phthalate & 60 & $117-81-7$ & & & & DEHP & 7.60 \\
\hline & Bis(2-ethylhexyl) terephthalate & 61 & $6422-86-2$ & & & & DEHTP & 8.39 \\
\hline & Bis(2-ethylhexyl) isophthalate & 62 & $137-89-3$ & & & & DOIP & 9.52 \\
\hline \multirow[t]{8}{*}{ Other classes } & 1,3,5-Triphenyl-1,5-pentanedione & 63 & $6263-84-9$ & & - & - & - & 5.24 \\
\hline & m-Aminophenylacetylene & 64 & $54060-30-9$ & & & - & 3-Ethynylaniline & 1.12 \\
\hline & $\beta$-Amyrone & 65 & - & - & & - & - & - \\
\hline & Squalene & 66 & $111-02-4$ & & & & Supraene & 14.1 \\
\hline & Indole & 67 & $120-72-9$ & & - & - & 2,3-Benzopyrrole & 2.14 \\
\hline & Indole, 3-methyl & 68 & $83-34-1$ & - & & - & Skatole & 2.60 \\
\hline & Tris(2-chloroisopropyl)phosphate & 69 & $13674-84-5$ & & - & - & Flame retardant TCPP & 2.59 \\
\hline & 1,2,4-Triazin-3-amine, 5,6-dimethyl- & 70 & $17584-12-2$ & - & & - & - & -0.65 \\
\hline
\end{tabular}




\section{The fate of organic contaminant species during the treatment processes}

In the study of the identified compounds from the selected samples, two scenarios were considered:

a) the water sample is homogeneous after leaving the equalization tank, and the compounds identified later on the treatment flow ( $S 2$ and $S 3$ ) are byproducts of the initial compounds;

b) each sample analyzed is unique, without direct links to confirm the transformation of the compounds or the decreases of organic carbon content between processes. In this case, the food production is a discontinuous process, for which reason the identified compounds could not be related to $S 1$ results. However, this situation is not applied for this study due to same ratio variation between TSS and organic extractible compounds for all samples.

In the first scenario, a direct dependence may be observed between the total suspended solid concentration $(984 \mathrm{mg} / \mathrm{L}, 648 \mathrm{mg} / \mathrm{L}$ and $86 \mathrm{mg} / \mathrm{L}$ for $S 1, S 2$ and $S 3)$ and the total peaks area of the corresponding samples on the GC chromatograms. The values of these two variables decrease during the stages of treatment by a linear trend for a correlation factor of 0.9998 . This correlation is explained by the compounds low solubility in water and high octanol partition $(\log \mathrm{P}>4)$ which means an increasing tendency of compounds adsorption to the solid particles. However, similar trend was also observed for the elimination of some compounds, but without correlation to chemical class or use category.

The role of the treatment steps used is to remove gradually the chemical contaminants up to the maximum limits set so that they can be safely discharged into the natural receptors.

In this paper, the $S 1$ data represent the initial results to which the following $S 2$ and $S 3$ results data will relate.

As can be seen in fig. 2 and table 1, the $S 1$ wastewater consists mainly of fatty acids $(44.10 \% \mathrm{n}$ hexadecanoic acid and $13.40 \%$ tetradecanoic acid) and some of their corresponding esters. Overall, only $29.75 \%$ area was removed after the DAF process, where the removal of level 1 compounds was $12.8 \%$, while for level 2 and 3 it was $80.7 \%$, respectively $93.8 \%$. A great impact of DAF was seen in saturated fatty acids complete removal, except palmitic acid (C16) which decreases insignificantly, by only $2.5 \%$. Another exception is oleic acid, which was better detected after flotation treatment. Initial $(S 1)$, the alkanes isomers interfere with oleic acid at the same retention time. After DAF, their corresponding peak area decreased with $75.7 \%$ for which reason oleic acid could be better identified, with a purity peak of $12.8 \%$ compared to the initial value, less than $5 \%$. This explains also the presence of other compounds as methylcycloheptane in $S 3$.

The completely eliminated compounds are some fatty acids esters type C12:C9 and C19:C1, the highest identified lipophilic ketone, 2-nonadecanone, versalide musk and the flame retardant tris(2chloroisopropyl) phosphate.

After the biological treatment step, the results indicate the removal of $72.0 \%$ of the total semivolatiles content reported to $S 2$, where $73.9 \%$ and $69.9 \%$ are organics of level 1 and 2 . The amount of unidentified organics increases up to $180 \%$.

For all systems, the C16 chain moiety is most abundant in the identified species, especially as nhexadecanoic acid (fig. 3). If the initial species area decreased for esters, alcohol, acid and haloalkanes, the C16:C1 FAE and 1-hexadecanol increased in intensity. The 1-hexadecanol is a byproduct of palmitic acid hydrogenolysis and hydrogenation [29] but can also be generated by enzymatic degradation (by hydroxylase) of n-hexadecane in the presence of Pseudomonas synxantha from petroleum sediments [30]. 


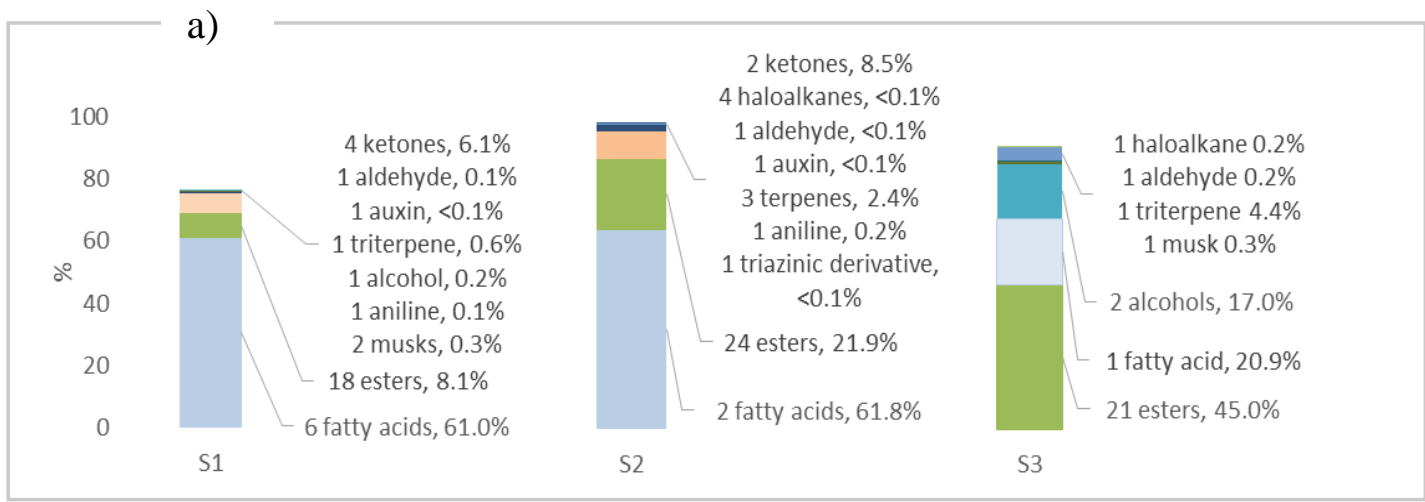

b)

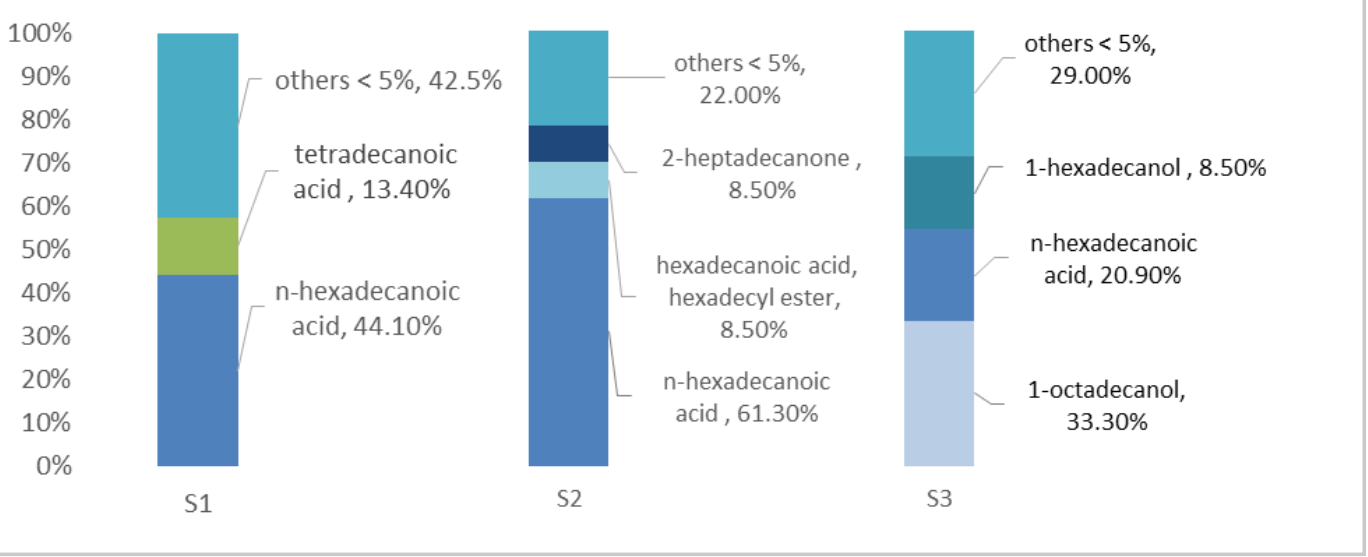

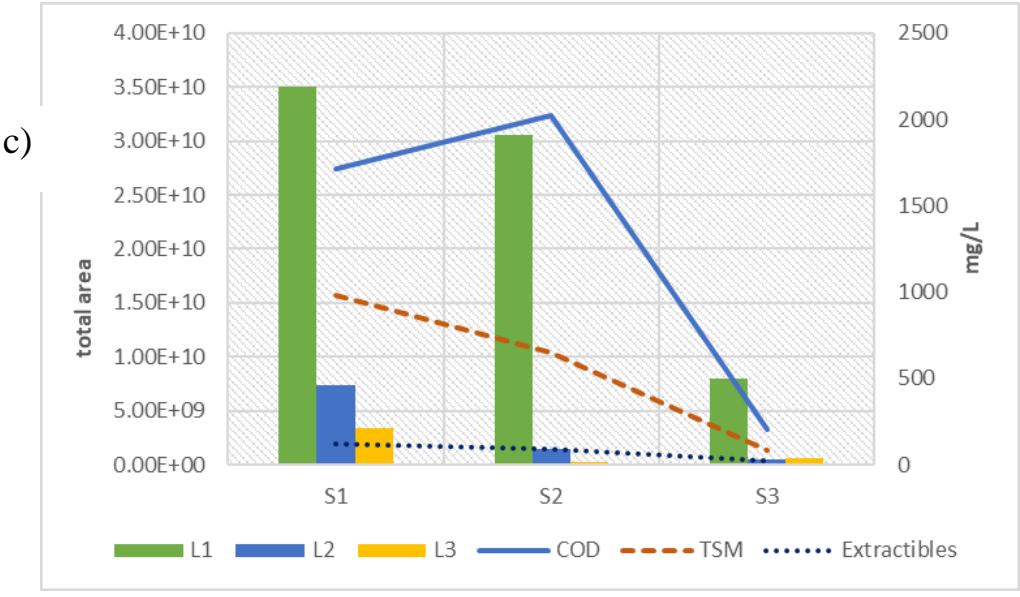

Fig. 2. Graphical representation of percentage fractions of total area by identified a) groups and b) individual compounds (level 1), and c) sum of peaks area of L1, L2 and L3 levels, for S1-S3 samples 

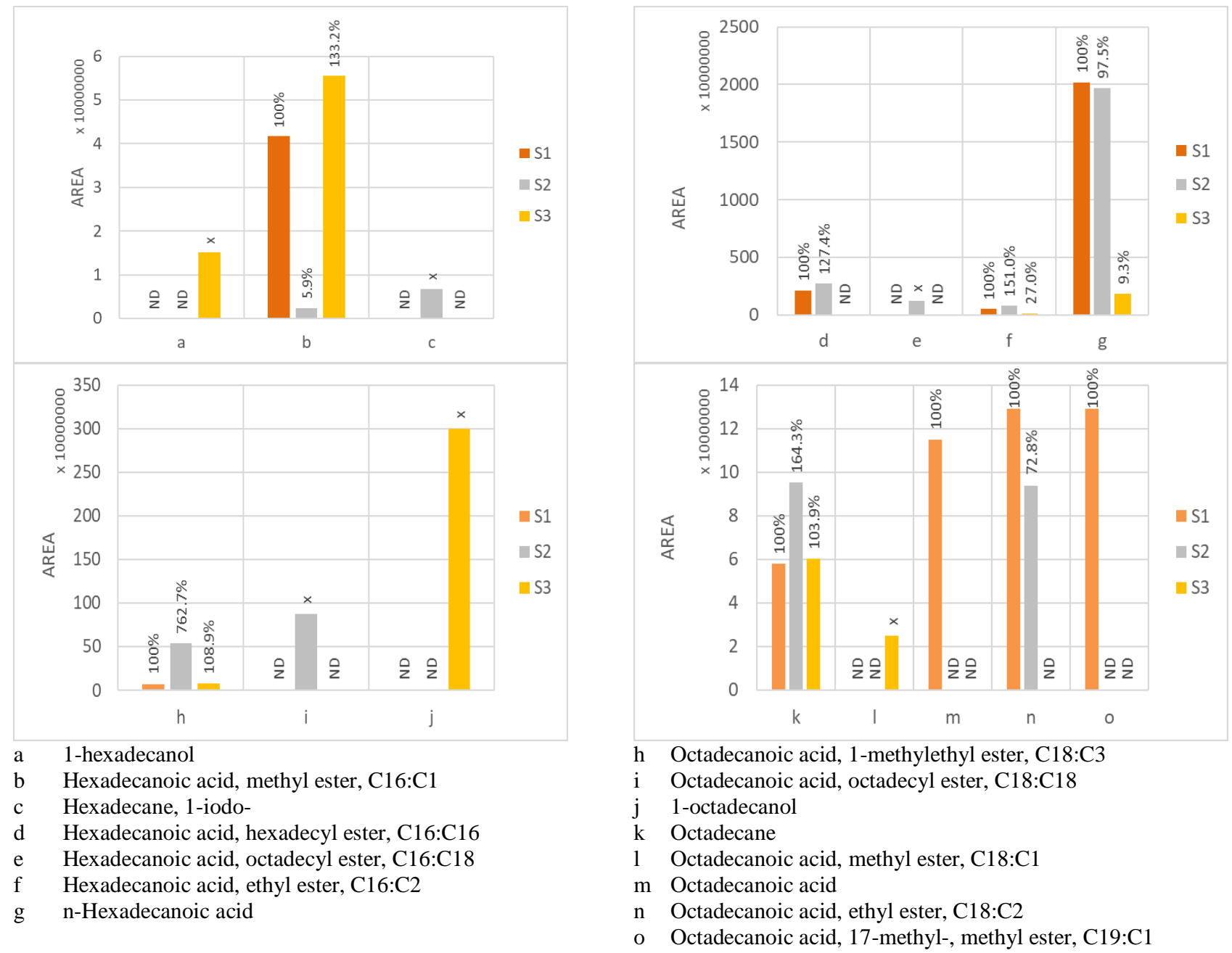

Fig. 3. Graphic representation of hexadecane and octadecane chain based species variation area for all three samples (S1-S3), where $N D$ is for not detected area, and $x$ for no reference area

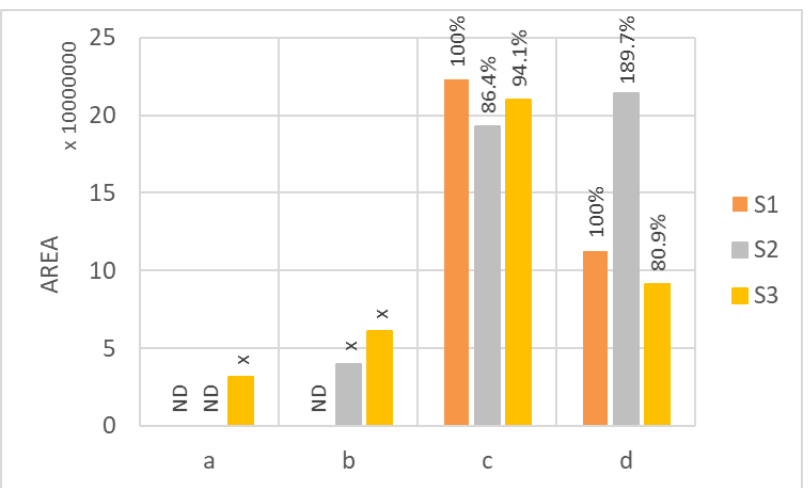

a Dibutyl phthalate

b Diisobutyl phthalate

c Bis(2-ethylhexyl) terephthalate

d Bis(2-ethylhexyl) phthalate - DEHP

Fig. 4. The phthalates amount detected in all three samples

Except C12:C12 ester, the FAE with C12-18:C9-18 are no longer found after biological treatment, but were identified aliphatic and cyclic alkanes with $\mathrm{C} 13-\mathrm{C} 18$ chain and long chain alcohols $\mathrm{C} 16$ and $\mathrm{C} 18$. In addition, it is observed the tendency of changing the ethyl moieties with methyl, as it is, for example, in the case of C18:C2 unsaturated geometric FAE isomers and C18:C1 FAE after the biological process. The formation of short chain fatty acids esters after activated sludge process was also emphasized in other studies [16].

None of the presented treatment steps, for the given operational parameters show any degradation efficiency regarding phthalates species, as can be seen in fig. 4. Phthalates stability in environmental samples is well known, being detected in all types of water samples, while their fate 
in WWTPs depends more on the adsorption on the activated sludge than on biodegradation. The most abundant phthalates are DEHP and its isomers [28].

In addition, all level 2 LCFA and FAE isomers and their related derivate were completely eliminated with biological treatment, being detected only the petroleum products (alkanes isomers).

\section{CONCLUSIONS}

Industrial wastewater treatment is challenging due to its complex chemical composition that requires the use of specific treatment steps. Conventional and advanced treatment technologies as dissolved air flotation and biological treatment with activated sludge were used.

Various species of organic compounds were detected in all samples, especially long chain fatty acids and their esters, alcohol and ketones derivatives. The most abundant organic was palmitic acid, known as n-hexadecanoic acid, a fatty acid. Other different types of compounds were identified as phthalates, triterpenes, musks and alcohol that are odours, surfactants or different plastic residues.

The treatment methods efficiency was observed in removing different compounds or decreasing their concentration based on compounds detected area and total suspended matter concentration. The combined dissolved air flotation method with biological treatment removed the semivolatiles with efficiencies of up to $80.3 \%$, while $29.8 \%$ were removed by only DAF. After biological treatment, the high amount of fatty acids and their esters decreases significantly due to either as sedimentation or as biodegradation process, with the generation of the high content of 1octadecanol.

\section{ACKNOWLEDGEMENTS}

This study has been conducted within the framework of the National Research Program "Nucleu", contract number 20N/2019, Project code PN 19040301.

\section{REFERENCES}

[1]. WANG, L. K., SHAMMAS, N. K., HUNG, Y. T., Handbook of Environmental Engineering, vol. 9, Humana Press, Totowa New Jersey, 2009, p. 1-57.

[2]. RAMESH. G.K., FLORA, J.R.V., CHEN, J.P., Handbook of Environmental Engineering, vol. 3, Humana Press, Totowa New Jersey, 2005, p. 21-45.

[3]. WANG, Y., GAO, W., WANG, Y., JIANG, G., J. Hazard. Mater, 376, 2019, p. 153.

[4]. GAGO-FERRERO, P., BLETSOU, A.A., DAMALAS, D.E., AALIZADEH, R., ALYGIZAKIS, N.A., SINGER, H. P., HOLLENDER, J., THOMAIDIS, N.S., J. Hazard. Mater, 387, 2020, https://doi.org/10.1016/j.jhazmat.2019.121712.

[5]. ASSRES, H.A., NYONI H., MAMBA B.B., MSAGATI T.A.M., Environ. Pollut., 253, 2019, p. 655.

[6]. HAShimoto, S., MATSUKAMI, H., IEDA, T., SUZUKI, G., Chemosphere, 276, 2021, https://doi.org/10.1016/j.chemosphere.2021.130085.

[7]. GU C., XU C., ZHOU Q., SHEN C., MA C., LIU S., YIN S., LI F., J. Clean. Prod., 320, 2021, https://doi.org/10.1016/j.jclepro.2021.128897.

[8]. CAMPOS-MANAS, M.C., PLAZA-BOLANOS, P., MARTINEZ-PIERNAS, A.B., SANCHEZ-PÉREZ, J.A., AGUERA, A., Chemosphere, 232, 2019, p. 152.

[9]. JAEN-GIL, A., BUTTIGLIERI, G., BENITO, A., GONZALEZ-OLMOS, R., BARCELO, D., SARRA, M., RODRIGUEZ-MOZAZ, S., Chem. Eng. J., 404, 2019, https://doi.org/10.1016/j.jhazmat.2019.120851.

[10]. LLORCA, M., LUCAS, D., FERRANDO-CLIMENT, L., BADIA-FABREGAT, M., CRUZMORATO, C., BARCELO, D., RODRIGUEZ-MOZAZ, S., J. Chromatogr. A., 1439, 2016, p. 124. [11]. TAKAZAWA, M., SUZUKI, S., NAKANO, T., TSUNOI, S., SHINOMIYA, M., J. Environ. Chem., 27, no.4, 2017, p. 137. 
[12]. LI, P., ZHAO, D., ZHANG, Y., SUN, L., ZHANG, H., LIAN, M., LI, B., Chem. Eng. J., 264, 2015, p. 595.

[13]. SUBHA, C., KAVITHA, S., ABISHEKA, S., TAMILARASAN, K., ARULAZHAGAN, P., RAJESH BANU, J., Fuel, 251, 2019, p. 224.

[14]. EDZWALD, J.K, Water Sci. Technol., 31, no. 3, 1995, p. 1.

[15]. SAIDULU, D., GUPTA, B., GUPTA, A. K., GHOSAL, P.S., J. Environ. Chem. Eng., 9, no. 4, 2021, https://doi.org/10.1016/j.jece.2021.105282.

[16]. WANG, J., LOU, Y., ZHOU, F.H., LIU, B., XIE, G., XING, D., J. Hazard. Mater, 423, part A, 2022, https://doi.org/10.1016/j.jhazmat.2021.127022.

[17]. U.S. EPA. Method 8270E (SW-846): Semivolatile Organic Compounds by Gas Chromatography/ Mass Spectrometry (GC/MS), Washington, DC, 2014, https://www.epa.gov/.

[18]. MANCINI, A., IMPERLINI, E., NIGRO, E., MONTAGNESE, C., DANIELE, A., ORRU, S., BUONO, P., Molecules, 20, no. 9, 2015, p. 17339, https://doi.org/10.3390/molecules200917339.

[19]. PARK, E.J., LEE, A.Y., PARK, S., KIM, J.H., CHO, M.H., Food Chem. Toxicol., 67, 2014, p. 26.

[20]. MALCA GARCIA, G.R., HENNIG, L., SIELER, J., BUSSMANN, R.W., Rev. Bras. Farmacogn., 25, no. 2, 2015, p. 92.

[21]. HAMID H.A., RAMLI A.N.M., YUSOFF M.M., Front Pharmacol., 8, 2017, https://doi.org/10.3389/fphar.2017.00096.

[22]. VON DER OHE, P., AALIZADEH, R., S13 | EUCOSMETICS | Combined Inventory of Ingredients Employed in Cosmetic Products (2000) and Revised Inventory (2006), Zenodo, 2020, https://doi.org/10.5281/zenodo.3959386.

[23]. U.S. ENVIRONMENTAL PROTECTION AGENCY. 2021. ECOTOX User Guide: Ecotoxicology Knowledgebase System. Version 5.3. Available: http:/www.epa.gov/ecotox/, [20.10.2021].

[24]. CHAOS, A., SANGRONIZ, A., GONZALEZ, A., IRIARTE, M., SARASUA, H.R., DEL RÍO, J., ETXEBERRIA, A., Polym. Int., 68, no. 1, 2018, p. 125.

[25]. STOTSKY, D.J., FLEMING, G.K., U.S. EPA. 2020. Supporting Information for Low-Priority Substance 1-Octadecanol. EPA's 20 Proposed Low-Priority and High-Priority Chemical Substances. [26]. DEEPIKA, S., OSMAN, M., KUMAR, M., SANDEEP, H., J. Agric. Eng., 57, no. 3, 2020, p. 259.

[27]. AUVIL, N.C., DE VASQUEZ, M.G.V., ALLEN, H.C., ACS Earth Space Chem., 5, no.10, 2021, p. 2947.

[28]. ClaRA, M., WINDHOFER, G., HARTL, W., BRAUN, K., SIMON, M., GANS, O., SCHEFFKNECHT, C., CHOVANEC, A., Chemosphere, 78, no. 9, 2010, p. 1078.

[29]. DUONGBIA, N., KANNARI, N., SATO, K., TAKARADA, T., CHAIKLANGMUANG, S., Alex. Eng. J, 2021, https://doi.org/10.1016/j.aej.2021.08.037.

[30]. MENG, L., LI, H., BAO, M., SUN, P., Sci. Rep., 7, 2016, https://doi.org/10.1038/srep39068.

Citation: Puiu, M.D., Short investigation on occurrence and removal of semivolatiles during wastewater treatment processes, Rom. J. Ecol. Environ. Chem., 2021, 3, no.2, pp. 130-140.

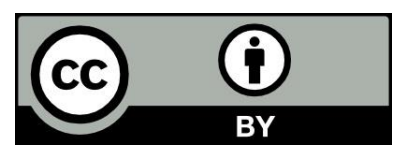

(C) 2021 by the authors. This article is an open access article distributed under the terms and conditions of the Creative Commons Attribution (CC BY) license (http://creativecommons.Org/licenses/by/4.0/). 